\title{
Safety Training Program for Clinical Laboratory Workers Regarding Prevention of Occupational Hazards
}

\author{
Amina Abd Elrazek Mahmoud*, Samah Said Sabry \\ Community Health Nursing, Faculty of Nursing, Benha University, Qalyobyia Governorate, Egypt \\ *Corresponding author: samahsaid662@yahoo.com
}

Received November 24, 2018; Revised December 29, 2018; Accepted January 15, 2019

\begin{abstract}
The practices of safety measures by the clinical laboratory workers in hospitals are necessary for the prevention of occupational hazards. The aim of this study was to evaluate the effect of safety training program for laboratory workers' regarding prevention of occupational hazards. Design: A quasi-experimental design was used in carrying out this study. Setting: The study was conducted at four governmental hospitals in Benha City: - are Benha University Hospital, Benha Teaching Hospital, Health Insurance Hospital, and Fever Hospital which included clinical laboratory. The sample of this study included convenient laboratory workers (100) whom are working at four hospitals were participated in this study. Tools: 1- A structured interviewing questionnaire for the socio-demographic characteristics of the laboratory workers, and their knowledge regarding occupational hazards, 2- An observational checklist for safe laboratory environment and practices of laboratory workers regarding prevention of the occupational hazards. Results: Showed a significant positive effect of the program on knowledge and practices of the laboratory workers $(\mathrm{P}<0.001)$. This study concluded that the program has positive effect to upgrade the laboratory workers' knowledge and improving their practices regarding prevention of occupational hazards $(\mathrm{P}<0.001)$. The study recommended that regulatory training program should be strengthened to ensure basic lab safety practices in hospitals, and providing training courses for large number of hospitals laboratory workers about prevention of occupational hazards and safety environmental condition.
\end{abstract}

Keywords: laboratory workers, occupational hazards, and laboratory safety

Cite This Article: Amina Abd Elrazek Mahmoud, and Samah Said Sabry, "Safety Training Program for Clinical Laboratory Workers Regarding Prevention of Occupational Hazards.” Journal Name, vol. 7, no. 2 (2019): 116-127. doi: 10.12691/ajnr-7-2-3.

\section{Introduction}

Occupational hazard is a hazard experienced in the workplace. It can encompass many types including chemical, biological, psychosocial, and physical hazards [1]. Many workers are unaware of the potential hazards in their work environment, which makes them more vulnerable to Laboratory hazards [2].

Laboratory environment contain hazardous substances. A hazardous substance is defined as a material/substance that poses a physical or health hazard. This includes both chemicals and biological agents. A physical hazard characteristics: Explosive, flammable, oxidizer, pyrophoric, organic peroxide, compressed gas, combustible liquid, unstable (Reactive) and water-reactive. A health hazard characteristic: carcinogen toxic or highly toxic, reproductive toxins, irritants, corrosives, sensitizers, hepatotoxins, nephrotoxins and neurotoxins [3].

Laboratory workers responsible practices and techniques are required when working with hazardous materials. So, primary barriers are referring to protective measures including engineering controls. This includes not only personal protective equipment but it also includes safety cabinets, fume hoods, vaccines and autoclaves, while secondary barriers are the facility design and construction. These barriers are to provide protection for the individuals outside the lab, the community, and the environment. In 2008 on of the staff was led to his death by sustained injuries due to a fire within the laboratory of the University of California in Los Angeles (UCLA), despite the strict safety precautions $[4,5]$.

Laboratories mainly have pathological (including some anatomical), highly infectious waste (small pieces of tissue, microbiological cultures, stocks of infectious agents, infected animal carcasses, blood and other body fluids), sharps, some radioactive and chemical waste. Special precautions must be taken to reduce the potential release of these agents. Each laboratory that is using an infectious agent must perform an additional lab specific training [6].

Laboratory safety guidelines have been established to minimize the hazards in a laboratory setting. It is important for the lab workers to take responsible actions and keep in mind that irresponsible acts could have lasting future effects. Training is also important for them to identify if the hazards increase, the risks increase, and the responsibility must increase. Personal habits play a large role in minimizing occupational hazards as not eating, 
drinking, smoking, chewing gum, applying cosmetics, removing contact lenses while being in the laboratory, not storing food or beverages in the lab or in chemical refrigerator, not mouth pipetting and washing hands before leaving laboratory or after handling contaminated material. Also, no open-toed shoes, no shorts unless a lab coat is used, restrain hair when working with hazardous materials, remove protective clothing in public and use the proper personal protective equipment for the job [7].

Hazardous laboratory chemicals include cancer-causing agents (carcinogens), toxins that may affect the liver, kidney, or nervous system, irritants, corrosives, and sensitizers, as well as agents that act on the blood system or damage the lungs, skin, eyes, or mucous membranes. OSHA rules limit all industry exposures to approximately 400 substances [10]. The sharp injuries resulted in 16,000 Hepatitis C Virus (HCV), 66,000 Hepatitis B Virus (HBV) and 1000 Human Immunodeficiency Virus (HIV) infections in health-care workers included the laboratory workers worldwide. Most of the public and several private-sector healthcare facilities are over-utilized, resulting in an explosive increase in the number of diagnostic laboratories in the City [11].

Community health nurse play an important role by educating and increase awareness among the laboratory workers about mechanical hazards may result from improper use, storage, or disposal of glassware as handle glassware carefully to avoid breakage that could cause injury or infection. Do not expose hot glassware to cold water (Allow hot glassware to cool before washing or placing in a sink.). Dispose of contaminated glass and sharp objects (microcapillary pipettes, Pasteur pipettes, and needles) in puncture-resistant containers, store sharp objects carefully to avoid skin punctures or cuts, wear safety goggles when using glassware on a burner and equipment/instruments as cover the back of long hair. And not operate new or unfamiliar equipment or instruments without proper training and authorization [12].

Community health nurse plays an important role by educating and increase awareness among the laboratories worker to specific precautions about all kinds of sharps and must be meticulously observed when handling body fluids of unknown origin because of the possible transmission of the AIDS and hepatitis Bb viruses in these specimens. Disposable gloves must be worn during the manipulation of these test materials. Masks, safety goggles, and laboratory coats are required; especially if aerosols and/or splattering of these fluids is likely to occur. Test specimens and supplies in contact with these fluids must be placed in a container of disinfectant prior to autoclaving $[8,13]$.

\subsection{Significance of the Study}

In Egypt, the calculated weighted mean prevalence for HBV and HCV among the general populations included health team was $6.7 \%$ and $13.9 \%$ respectively. In Egypt, assessment of lab safety is not a regular activity in most of the organizations, whereas it could be occurred in limited levels in the laboratories such as at EL-Mansoura University. As far as it is known, chemical lab safety is not assessed in Benha University. Laboratory safety is a careful process, with the target of preventing injuries and diseases among laboratory personnel. This includes scientists, technicians, nurses and cleaning workers. Occupational Safety Health Administration (OSHA). In recent years, there have been serious accidents in laboratories, which included fatalities that could have been prevented by using safer laboratories procedures. This may be due to ignoring the use of personal protective equipment, and disregarding standard operating procedures by the lab workers [14].

Laboratory workers are at risk of infection with blood-borne pathogens (BBP) through occupational exposure to blood and infectious body fluids. Percutaneous exposure to blood, blood products, and infectious body fluids presents the greatest risk for transmission in the laboratory and health care setting [15].

\subsection{Aim of the Study}

The study aimed to evaluate the effect of the safety training program for clinical laboratory workers regarding prevention of occupational hazards.

\subsection{Research Hypotheses}

The safety training program will improve knowledge and practices of clinical laboratory workers regarding prevention of occupational hazards

\section{Subjects and Methods}

\subsection{Research Design}

A quasi experimental design was utilized to carry out this study.

\subsection{Study Setting}

The present study was conducted at four governmental hospitals which included clinical laboratory, in Benha City. These four hospitals are Benha University Hospital, Benha Teaching Hospital, Health Insurance Hospital, and Fever Hospital.

\subsection{Study Subjects}

A convenient sample was used in this study, the total number of studied clinical laboratory workers in the above mentioned setting were 100, whom divided according the place of work as: Benha University Hospital (40), Benha Teaching Hospital (28), Health Insurance Hospital (20), and Fever Hospital (12).

\subsection{Tools of data Collection}

Two tools were used for data collection, interviewing questionnaire and observational checklist.

Tool I: A structured interviewing questionnaire: It consisted of the following two parts:

Part one: Socio-demographic characteristics of the laboratory workers. It included 10 items about age, gender, education, residence, nature of job, years of experience, income, received training courses about Lab safety, number and place of training courses. 
Part two: Designed to assess the laboratory workers' knowledge which included 16 items divided as: a) knowledge about occupational health hazards (7 items), and b) knowledge about laboratory safety ( 9 items). Scoring system; for each question was given as follows: 2 if complete answer, 1 if incomplete answer and 0 if don't know. The total knowledge scores were considered good if the score of the total knowledge $\geq 75 \%$, considered average if it is equals $50-<75 \%$, and considered poor if it is less than $50 \%$.

Tool II: An observational checklist. It consisted of the following two parts:

Part one: It was concerned with observation the hospital safety environmental condition which included 12 items about cleanliness laboratory area, walls and ground, basin and its surrounding area, laboratory equipment, tables, keep equipment in clean and safe place, tab water supply, ventilation, label code and precaution on chemical substances, safe personal protective equipment, soft wired nets on the windows, and lightening in the kitchen. This part used only before implementing the program. Scoring system: Each item was assigned a score of: 1 if present, and Zero if not present.

Part two: It was concerned with the laboratory workers' practices regarding prevention of the occupational hazards, which included 5items divided into (53 questions) divided into: 11 about laboratory dress code, 11 about good personal hygiene, 5 about good housekeeping practices, 18 about good laboratory technique, and 8 about decontamination procedure. Scoring system: Practices score for each answer was given as follows: 2 if done completely, and 1 if done incompletely.

The total practice were considered satisfactory if the score of the total practices equals $\geq 75 \%$, and considered unsatisfactory if it is less than $75 \%$.

\subsection{Content Validity \& Reliability}

The tools were revised for content validity by 3 juries who were experts in the Community Health Nursing Specialties, for clarity, relevance, comprehensiveness, and applicability. According to their suggestions, the modifications were applied. Reliability of the tools was applied by the researcher for testing the internal consistency of the tool, by administration of the same tools to the same subjects under similar condition on one or more occasion. Answers from repeated testing were compared (test- re -test reliability).

\subsection{Field Work}

- Preparation of data collection tools was carried out over a period of eight months from the beginning of March 2018 to end of October 2018, including experts' opinions, validity, and reliability test were equal 0.81 for knowledge and 0.76 for practices).

- Official permissions were obtained from the deans of the Faculty of Nursing- Benha University, also from administrator of the studied Hospitals.

\subsection{Program Construction}

The current study was carried out on four phases, preparatory phase, development phase, implementation phase and evaluation phase.
1. Preparatory phase: The program was designed after extensive review of related literature, by the researchers. Based on results obtained from pre-assessment tools, it was revised and modified.

2. Program development phase: The program was developed based on the actual results that were obtained from pre-program assessment using a structured interviewing questionnaire sheet, literature review which aimed to enhance the Laboratory workers knowledge, and practices toward Laboratory workers.

An objective of the program was to improve laboratory knowledge and practices toward laboratory safety.

Contents of program: The content of the program was designed to meet the laboratory workers needs toward laboratory hazards and laboratory safety measures and to fit into their interest and level of understanding. Its contents were:

*Occupational health hazards (chemical, biological, physical, mechanical, ergonomic, electrical, and psychological hazards)

*Laboratory safety measures to prevent occupational hazards (general personal safety, eye safety, safe handling of biological hazardous material, chemical and gas safety, radiation safety, fire safety, fire safety, electrical safety, severe weather safety, and in case of accidents). Also importance of laboratory dress code, good personal hygiene, decontamination procedure and good laboratory technique and good housekeeping practices). *Safety laboratory (water supply, clean laboratory area, clean tables, suction fans for ventilation, label code and precaution on chemical substances, soft wired nets on the windows, and good lightening in the Lab and keep clean laboratory equipment in safe place).

3. Program implementation phase: The program was implemented in a period of eight months, from the beginning of March 2018 to the end of October 2018. Implementation of the program was carried out at 4 governmental hospitals. The subject material used has been sequenced through the 7 sessions (3 session for theory and 4 sessions for practices). The duration of each session ranged from 20 to 30 minutes including times for discussion according to workers' achievement, progress and feedback. The sessions contained knowledge about laboratory hazards and laboratory safety measures.

The workers were divided into small groups; each group included about 10 workers. The three sessions were implemented for each group separately for 2 weeks (2 days/week), in addition to one week for pre and posttest. Sometimes the researcher worked with two groups in the same day. At the beginning of the first session, an orientation to the program and its purpose took place. After each session, a feedback about the previous session was done as well as the objectives of the new topics were mentioned. Methods of teaching included lectures, group discussions, demonstrations, re-demonstration and role play. An instructional media was used including an illustrated booklet and purchure.

4. Program evaluation phase: After the implementation of the program, the post-test was done to workers to assess knowledge, and practices by the same format of the pretest to evaluate the effectiveness of the implemented program. This was done immediately after the intervention of program implementation. 


\subsection{Pilot Study}

After the development of the tools, a pilot study was carried out on $10 \%$ of the sample (10 workers) to ascertain the clarity, applicability, feasibility of the tool, to estimate the exact time needed to fill in the questionnaire, and to detect any problems that might face the researcher and interfere with data collection. After conducting the pilot study, minor necessary changes were done, the tool was then finalized. The pilot sample was included in the main study sample.

\subsection{Administrative and Ethical Considerations}

Official permission was obtained by submission of an official letter from the Faculties of Nursing to the responsible authorities of the study settings to obtain the permission for data collection.

Personal communication was done with workers to explain the purpose of the study, assure their best possible cooperation and ensuring confidentiality of the data. The researchers emphasized to workers that the study was voluntary and anonymous. Workers had the full right to refuse to participate in the study or to withdraw at any time without giving any reason.

\section{Statistical Analysis}

The collected data were verified prior to computerized entry; statistical analysis was done by using the Statistical Package for Social Science (SPSS) version 20. Data were presented in tables by using mean, standard deviation, number, percentage distribution, and Chi- Square and non-parametric tests (r). Statistical significance was considered at: P- Value $>0.05$ insignificant, P- Value < 0.05 significant, $\mathrm{P}-$ Value $<0.001$ highly significant.

\section{Results}

Table 1 shows that; $54 \%$ of the studied laboratory workers aged from 30 to less than 40 years old with $\mathrm{X} \pm \mathrm{SD}=32.70 \pm 9.41 .67 \%$ of them were male, and $67 \%$ of them were living in rural area. As regard experience years; $67 \%$ of them had less than five years of experience. Income was enough for $42 \%$ of them while weren't enough for only38 \% of them. This table also shows that; $42 \%$ of the laboratory workers received training courses about laboratory safety measures. As regards number of courses $52.38 \%$ of them received less than 3 courses while $48 \%$ of them received 3 courses or more. According to the place of courses; $42.85 \%$ of them taken the courses inside the hospital.

Figure 1 shows that; $43 \%$ of the studied laboratory workers had secondary education while $27 \%$ had basic education, and $15 \%$ of them had high education and post graduate.

Figure 2 illustrates that; $49 \%$ of the studied laboratory workers were employee while $32 \%$ of them were technician workers and $11 \%$ of them were laboratories doctor, and $8 \%$ were cleaning workers.

Table 1. Frequency distribution of the studied laboratory workers according to their socio-demographic characteristics $(n=100)$

\begin{tabular}{|c|c|c|}
\hline Socio-demographic characteristics & No. & $\%$ \\
\hline Age / years & & \\
\hline$\leq 20$ & 19 & 19.00 \\
\hline $30-$ & 54 & 54.00 \\
\hline $40+$ & 27 & 27.00 \\
\hline $\mathrm{X} \pm \mathrm{SD}=32.70 \pm 9.41$ & \multicolumn{2}{|c|}{ Range $=\mathbf{3 0 . 0 0}$} \\
\hline \multicolumn{3}{|l|}{ Gender } \\
\hline Male & 67 & 67.00 \\
\hline Female & 33 & 33.00 \\
\hline \multicolumn{3}{|l|}{ Residence } \\
\hline Rural & 67 & 67.00 \\
\hline Urban & 33 & 33.00 \\
\hline \multicolumn{3}{|l|}{ Experience years } \\
\hline$<5$ & 67 & 67.00 \\
\hline $5+$ & 33 & 33.00 \\
\hline \multicolumn{3}{|l|}{ Monthly Income } \\
\hline Enough and saving & 10 & 10.00 \\
\hline Enough only & 42 & 42.00 \\
\hline Not enough & 38 & 38.00 \\
\hline Received training courses & 42 & 42.00 \\
\hline \multicolumn{3}{|l|}{ No. of courses $(n=42)$} \\
\hline$<3$ & 22 & 52.38 \\
\hline$\geq 3$ & 20 & 47.62 \\
\hline \multicolumn{3}{|l|}{ The place of courses $(n=42)$} \\
\hline Inside the hospital & 18 & 42.85 \\
\hline Outside the hospital & 24 & 57.15 \\
\hline
\end{tabular}

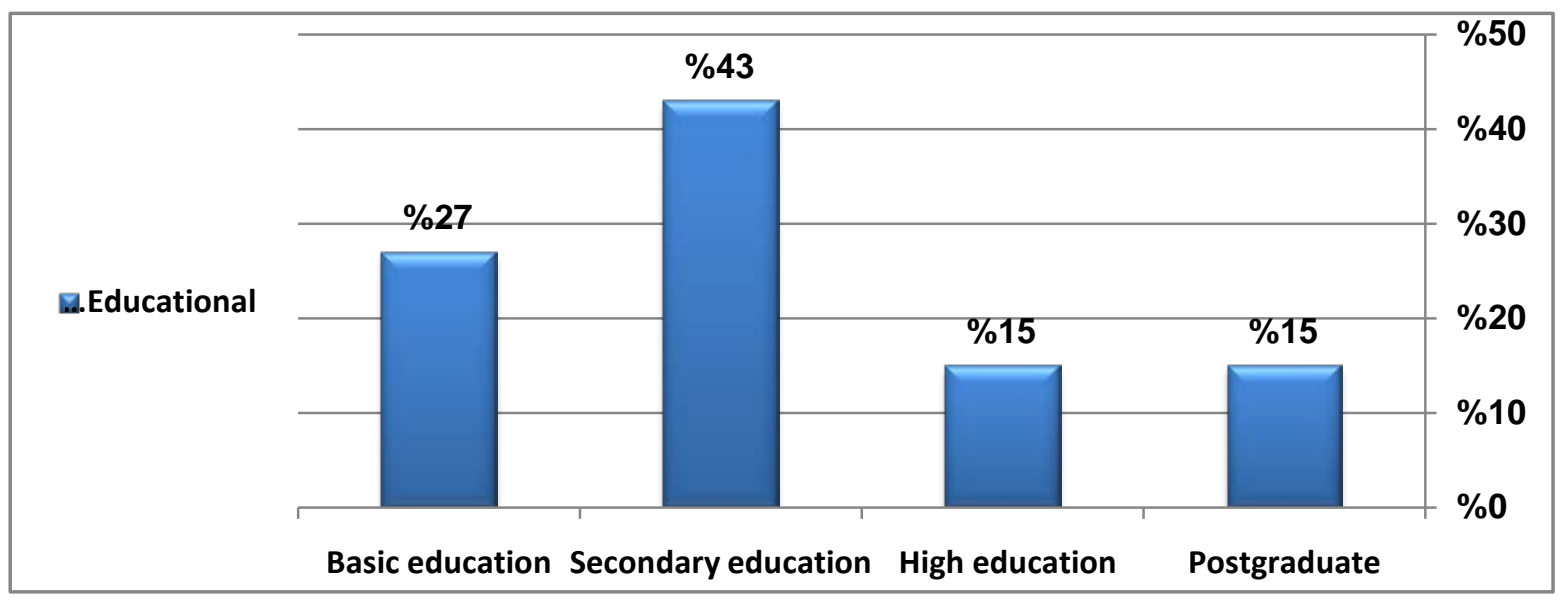

Figure 1. Percentage distribution of the studied laboratory workers according to their educational levels (n=100) 


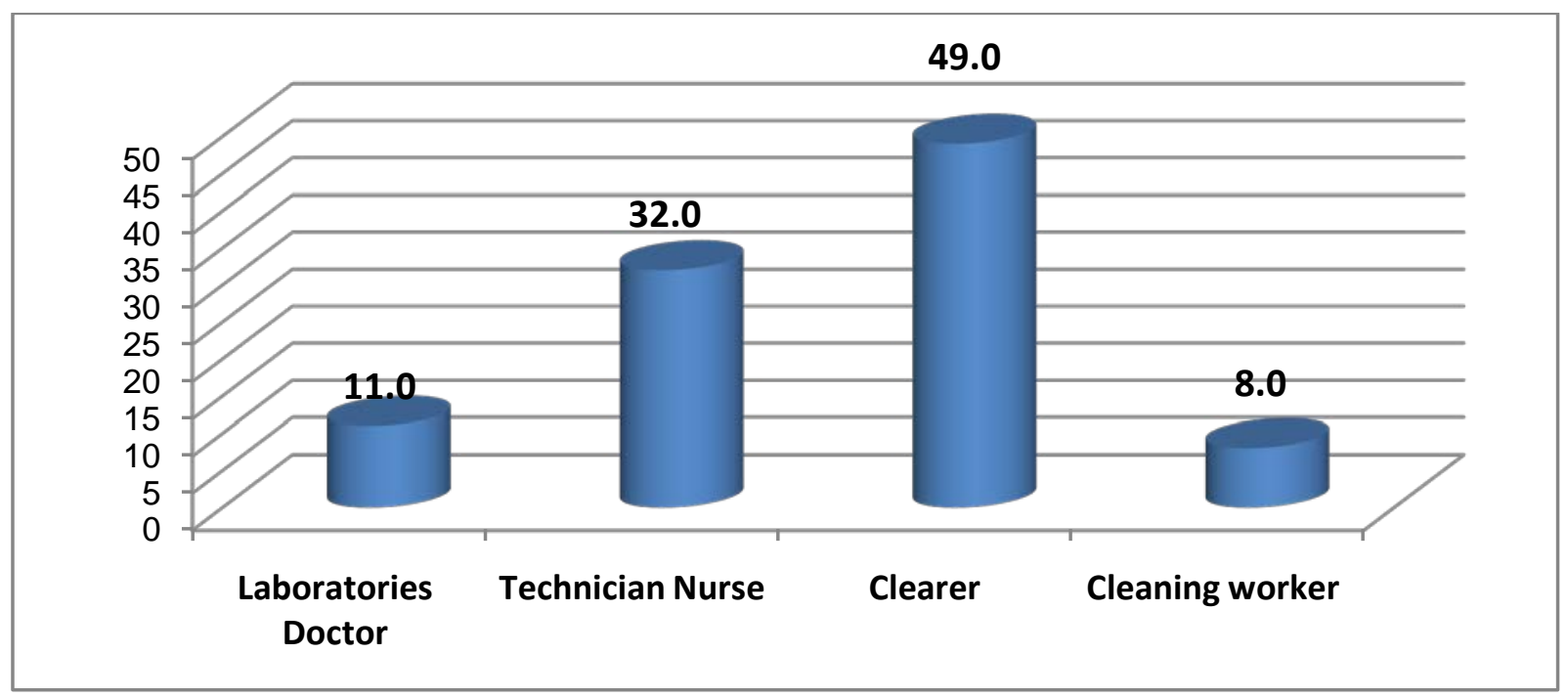

Figure 2. Percentage distribution of the laboratory workers categories according to their nature of job $(n=100)$

Table 2 describes that, all $100 \%$ of the studied hospitals laboratory had tap water supply, while $75 \%$ of them had clean laboratory area, clean tables, suction fans for ventilation, label code and precaution on chemical substances, soft wired nets on the windows, and good lightening in the Lab and $25 \%$ of them had clean laboratory equipment, and keep equipment in clean and safe place.

Table 3 explains that; the studied laboratory workers' knowledge regarding to laboratory health hazards (chemical, biological, physical, mechanical, ergonomic, electrical, and psychological hazards) improved significantly after the program implementation $(\mathrm{P}<0.001)$.

Table 4 explains that; the studied laboratory workers' knowledge about laboratory safety (general personal safety, eye safety, safe handling of biological hazardous material, chemical and gas safety, radiation safety, fire safety, fire safety, electrical safety, severe weather safety, and in case of accidents) improved significantly after the program implementation ( $\mathrm{P}<0.001)$.

Figure 3 illustrates that, before the program implementation; $23 \%$ of the of the laboratory workers had good total knowledge scores regarding laboratory safety, while after the program implementation total knowledge scores increased to $62 \%$.

Table 5 shows that; the variable "laboratory dress code "were done completely for $38 \%$ of the studied laboratory workers before the program implementation and increased to $90 \%$ after the program. While the variable" good personal habits "was $45 \%$ before the program implementation and increased to $81 \%$ after the program implementation, the variable" decontamination procedure" was $43 \%$ before the program implementation and increased to $76 \%$ after the program implementation, and the variables "good laboratory technique and good housekeeping practices" were 41\%, $33.33 \%$ respectively before the program implementation and increased to $70 \%$, $71 \%$ respectively after the program There were high statistically significant differences $(\mathrm{P}<0.001)$.

Figure 4 illustrates that; before the program implementation; only $44 \%$ of the laboratory workers had satisfactory practices regarding laboratory safety measures, while after the program implementation increased tendency to $72 \%$.
Table 6 reveals that; there were high statistically significant differences between the studied laboratory workers' total knowledge scores and their age, gender, educational levels, nature of job, experience years, and their received training courses $(\mathrm{P}<0.001)$.

Table 7 reveals that; there were highly statistically significant differences between total practices scores of the studied laboratory workers regarding prevention of laboratory hazards and their educational levels, nature of job, experience years, and their received training courses $(\mathrm{P}<0.001)$.

Table 8 shows that, highly statistically significant positive correlation coefficient between total knowledge and practices scores of the studied laboratory workers $(\mathrm{P}<0.001)$.

\section{- According to the research hypothesis}

The safety program will improve the laboratory workers knowledge and practices to prevent occupational hazards (Table 2, Table 3, Table 4, Table 5 \& Figure 3).

Table 2. Frequency distribution of laboratory safety environment of the studied laboratory' hospital (n= 4 hospitals)

\begin{tabular}{|l|c|c|c|c|}
\hline \multirow{2}{*}{ Laboratory Safety Environment } & \multicolumn{2}{|c|}{ Yes } & \multicolumn{2}{c|}{ No } \\
\cline { 2 - 6 } & No. & $\%$ & No. & $\%$ \\
\hline Clean laboratory area. & 3 & 75.0 & 1 & 25.0 \\
\hline Clean laboratory walls and ground. & 2 & 50.0 & 2 & 50.0 \\
\hline Clean basin and its surrounding area. & 2 & 50.0 & 2 & 50.0 \\
\hline Clean laboratory equipment. & 1 & 25.0 & 3 & 75.0 \\
\hline Clean tables. & 3 & 75.0 & 1 & 25.0 \\
\hline Keep equipment in clean and safe place. & 1 & 25.0 & 3 & 75.0 \\
\hline Present tap water supply. & 4 & 100.0 & 0 & 0.0 \\
\hline Present of suction fans for ventilation. & 3 & 75.0 & 1 & 25.0 \\
\hline $\begin{array}{l}\text { Present label code and precaution on } \\
\text { chemical substances. }\end{array}$ & 3 & 75.0 & 1 & 25.0 \\
\hline $\begin{array}{l}\text { Present safe personal protective } \\
\text { equipment. }\end{array}$ & 2 & 50.0 & 2 & 50.0 \\
\hline Present of soft wired nets on the windows. & 3 & 75.0 & 1 & 25.0 \\
\hline Present good lightening in the Lab. & 3 & 75.0 & 1 & 25.0 \\
\hline
\end{tabular}


Table 3. Statistically differences of laboratory workers' knowledge about occupational health hazards pre and post intervention program $(\mathbf{n}=\mathbf{1 0 0})$

\begin{tabular}{|c|c|c|c|c|c|c|c|c|}
\hline \multirow{2}{*}{ Occupational Health Hazards } & \multicolumn{3}{|c|}{ Before- program (\%) } & \multicolumn{3}{|c|}{ After- program (\%) } & \multirow{2}{*}{$X^{2}$} & \multirow{2}{*}{ P-value } \\
\hline & Complete & Incomplete & Don't know & Complete & Incomplete & Don't Know & & \\
\hline Chemical Hazards & 0.00 & 36.00 & 64.00 & 16.00 & 45.00 & 39.00 & 173.407 & $<0.000^{* *}$ \\
\hline Biolaogical hazards & 11.00 & 37.00 & 52.00 & 33.00 & 47.00 & 20.00 & 168.485 & $<0.000^{* *}$ \\
\hline Physical hazards & 37.00 & 10.00 & 53.00 & 58.00 & 19.00 & 23.00 & 117.426 & $<0.000^{* *}$ \\
\hline Mechanical hazards & 2.00 & 52.00 & 46.00 & 25.00 & 55.00 & 20.00 & 161.636 & $<0.000 * *$ \\
\hline Ergonomic hazards & 7.00 & 40.00 & 53.00 & 18.00 & 42.00 & 40.00 & 164.135 & $<0.000 * *$ \\
\hline Electrical hazards & 11.00 & 29.00 & 60.00 & 13.00 & 49.00 & 38.00 & 173.927 & $<0.000^{* *}$ \\
\hline Psychological hazards & 13.00 & 70.00 & 17.00 & 28.00 & 63.00 & 9.00 & 223.423 & $<0.000^{* *}$ \\
\hline
\end{tabular}

** Highly statistically significant difference $(\mathrm{P} \leq 0.001)$.

Table 4. Percentage distribution of statistical differences between before \& after the laboratory workers knowledge regarding laboratory safety $(\mathbf{n}=\mathbf{1 0 0})$

\begin{tabular}{|c|c|c|c|c|c|c|c|c|}
\hline \multirow{2}{*}{ Laboratory Safety Knowledge } & \multicolumn{3}{|c|}{ Before- program (\%) } & \multicolumn{3}{|c|}{ After- program (\%) } & \multirow{2}{*}{$X^{2}$} & \multirow{2}{*}{ P-value } \\
\hline & Complete & Incomplete & Don't know & Complete & Incomplete & Don't Know & & \\
\hline General Personal Safety & 4.00 & 19.00 & 77.00 & 16.00 & 5300 & 31.00 & 196.040 & $<0.000^{* * *}$ \\
\hline Eye Safety & 13.00 & 20.00 & 67.00 & 15.00 & 35.00 & 50.00 & 195.667 & $<0.000^{* *}$ \\
\hline $\begin{array}{l}\text { Safe Handling of Biologically } \\
\text { Hazardous Material }\end{array}$ & 12.00 & 22.00 & 66.00 & 26.00 & 53.00 & 21.00 & 196.040 & $<0.000^{* *}$ \\
\hline Chemical and Gas Safety & 16.00 & 32.00 & 52.00 & 28.00 & 40.00 & 32.00 & 200.000 & $<0.000^{* * *}$ \\
\hline Radiation Safety & 14.00 & 19.00 & 67.00 & 37.00 & 30.00 & 33.00 & 188.350 & $<0.000^{* * *}$ \\
\hline Fire Safety & 14.00 & 40.00 & 16.00 & 78.00 & 12.00 & 10.00 & 126.01 & $<0.000 * *$ \\
\hline Electrical Safety & 12.00 & 68.00 & 20.00 & 31.00 & 58.00 & 11.00 & 33.85 & $<0.000^{* *}$ \\
\hline Severe Weather Safety & 37.00 & 43.00 & 20.00 & 90.00 & 20.00 & 18.00 & 62.67 & $<0.000 * *$ \\
\hline In Case of Accidents & 15.00 & 25.00 & 60.00 & 80.00 & 30.00 & 17.00 & 105.03 & $<0.000^{* *}$ \\
\hline
\end{tabular}

** Highly statistically significant difference $(\mathrm{P}<0.001)$.

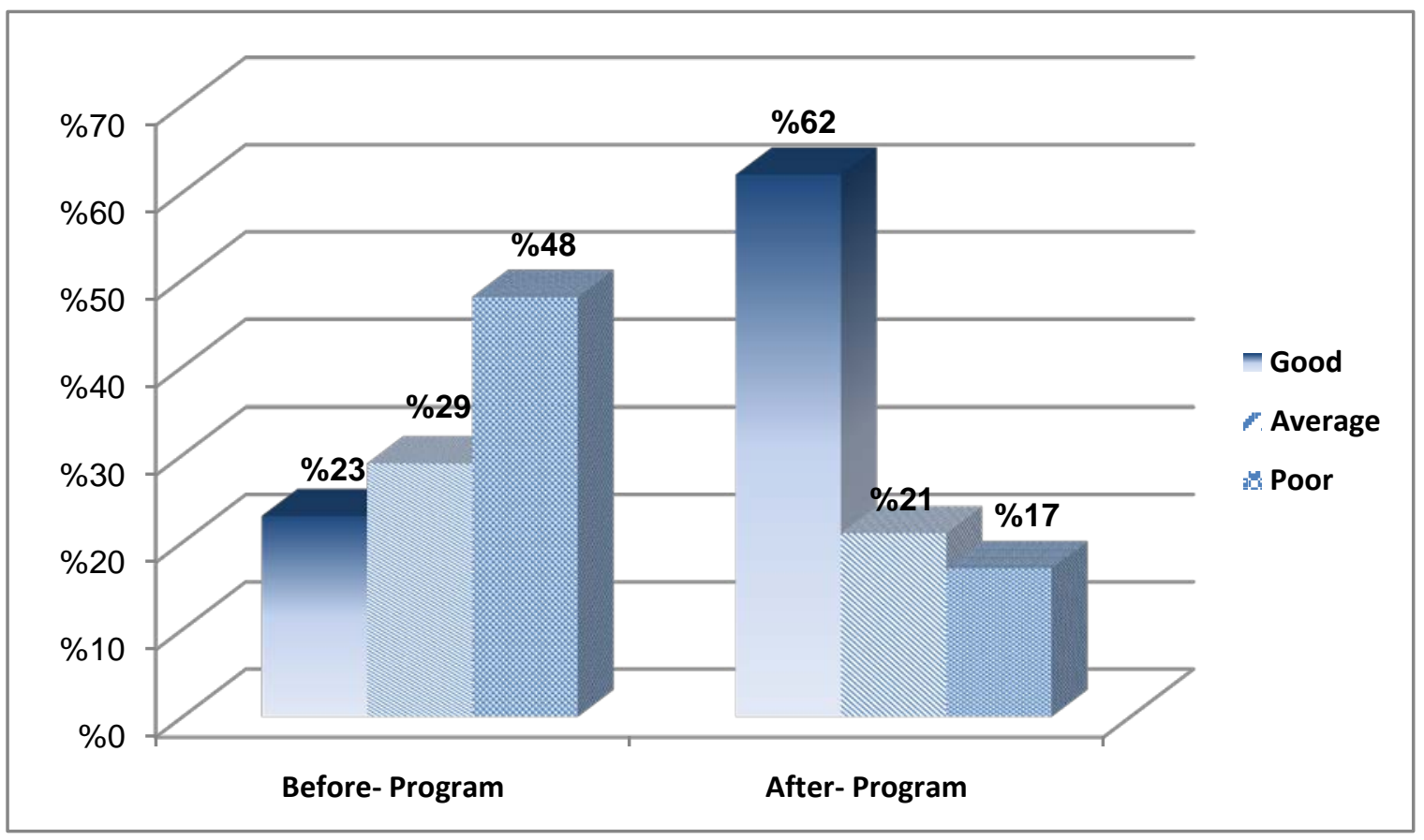

Figure 3. Percentage distribution of the laboratory workers' total knowledge score regarding laboratory safety before \& after the program implementation $(n=100)$ 
Table 5. Percentage distribution of statistical differences between before $\&$ after the program implementation regarding laboratory safety practices of the studied laboratory workers $(n=100)$

\begin{tabular}{|l|c|c|c|c|c|c|}
\hline \multirow{2}{*}{ Practices } & \multicolumn{2}{|c|}{ Before- program (\%) } & \multicolumn{2}{c|}{ After- program (\%) } & \multirow{2}{*}{$\mathbf{X}^{2}$} & \multirow{2}{*}{ P-value } \\
\cline { 2 - 5 } & Done Completely & Done Incompletely & Done Completely & Done Incompletely & & \\
\hline Laboratory Dress Code & 38.00 & 62.00 & 90.00 & 10.00 & 6.94 & $<0.001^{* *}$ \\
\hline Good Personal Habits & 45.00 & 55.00 & 81.00 & 19.00 & 5.91 & $<0.001^{* *}$ \\
\hline Good Housekeeping Practices & 33.00 & 67.00 & 72.66 & 28.00 & 6.54 & $<0.001^{* *}$ \\
\hline Good Laboratory Techniques & 41.00 & 59.00 & 70.00 & 30.00 & 4.23 & $<0.001^{* *}$ \\
\hline Decontamination Procedure & 43.00 & 57.00 & 76.00 & 24.00 & 5.33 & $<0.001^{* *}$ \\
\hline
\end{tabular}

** Highly statistically significant difference $(\mathrm{P}<0.001)$.

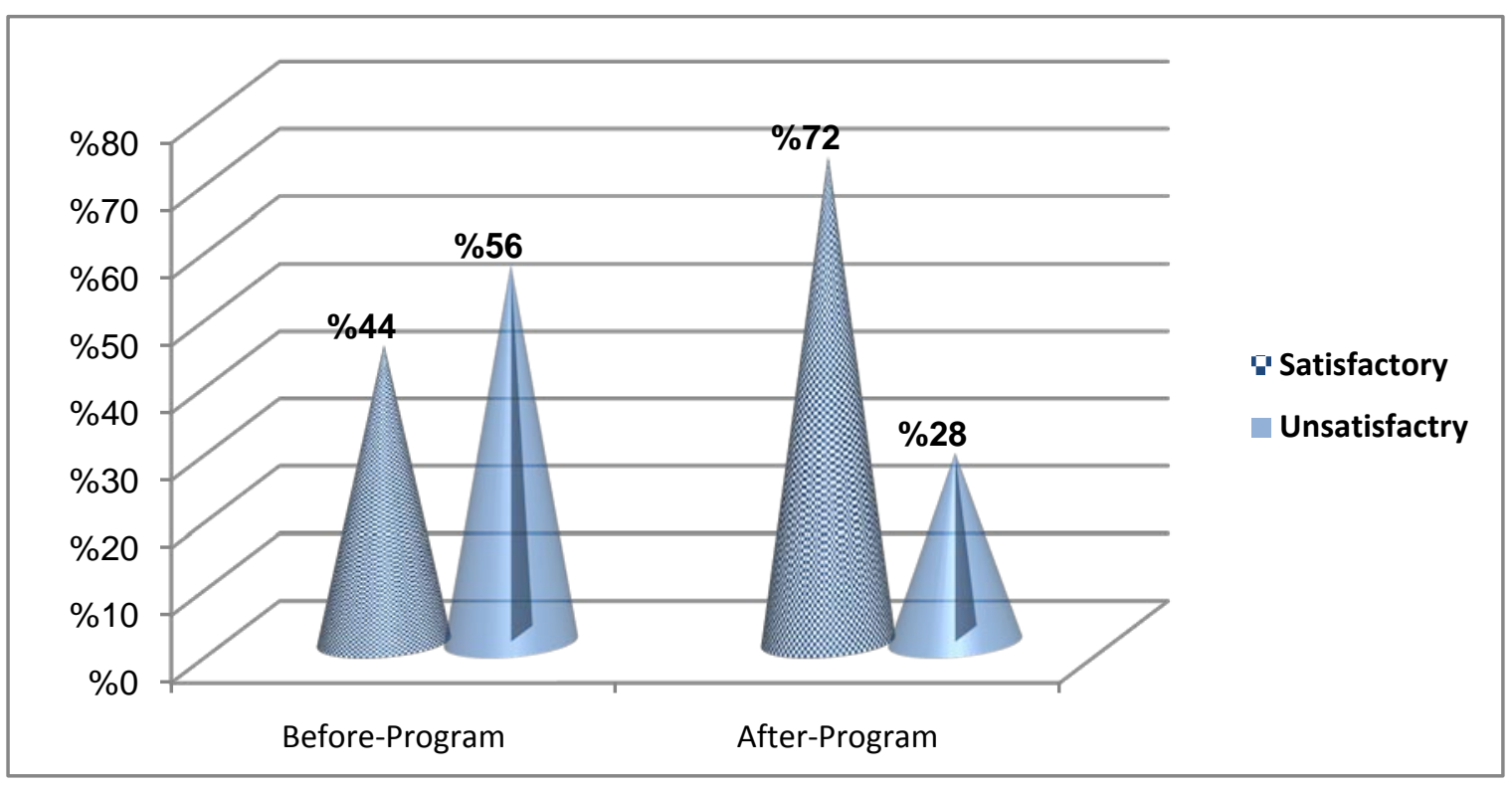

Figure 4. Percentage distribution of laboratory workers' total practices scores regarding laboratory safety measures before \& after the program implementation $(n=100)$

Table 6. Statistically relation the laboratory workers' total knowledge scores \& their socio-demographic characteristics training courses about laboratory safety $(\mathbf{n}=100)$

\begin{tabular}{|c|c|c|c|c|c|c|c|c|}
\hline \multirow{3}{*}{ Socio-demographic Characteristics } & \multicolumn{6}{|c|}{ Total knowledge } & \multicolumn{2}{|c|}{ Chi-Square } \\
\hline & \multicolumn{3}{|c|}{ Before- program (\%) } & \multicolumn{3}{|c|}{ After- program (\%) } & \multirow{2}{*}{$\mathrm{X}^{2}$} & \multirow{2}{*}{ P-value } \\
\hline & Good & Average & Poor & Good & Average & Poor & & \\
\hline \multicolumn{9}{|l|}{ Age / years } \\
\hline$\leq 20$ & 2.00 & 8.00 & 9.00 & 10.00 & 5.00 & 4.00 & \multirow{3}{*}{12.76} & \multirow{3}{*}{$<0.001^{* *}$} \\
\hline $30-$ & 9.00 & 17.00 & 28.00 & 27.00 & 10.00 & 17.00 & & \\
\hline $40+$ & 7.00 & 12.00 & 8.00 & 16.00 & 6.00 & 5.00 & & \\
\hline \multicolumn{9}{|l|}{ Gender } \\
\hline Male & 13.00 & 24.00 & 30.00 & 38.00 & 10.00 & 19.00 & 11.02 & $<0.001^{* *}$ \\
\hline Female & 9.00 & 4.00 & 20.00 & 18.00 & 11.00 & 3.00 & & \\
\hline \multicolumn{9}{|l|}{ Educational level } \\
\hline Basic education & 7.00 & 7.00 & 13.00 & 15.00 & 5.00 & 7.00 & \multirow{4}{*}{63.57} & \multirow{4}{*}{$<0.001^{* *}$} \\
\hline Secondary education & 20.00 & 16.00 & 7.00 & 32.00 & 9.00 & 3.00 & & \\
\hline University education & 8.0 & 5.00 & 3.00 & 10.00 & 5.00 & 0.00 & & \\
\hline Postgraduate & 10.00 & 4.00 & 1.00 & 12.00 & 3.00 & 0.00 & & \\
\hline \multicolumn{9}{|l|}{ Nature of work } \\
\hline Laboratories Doctor & 8.00 & 3.00 & 0.00 & 11.00 & 0.00 & 0.00 & \multirow{4}{*}{36.64} & \multirow{4}{*}{$<0.001^{* *}$} \\
\hline Technician Nurse & 16.00 & 9.00 & 7.00 & 23.00 & 6.00 & 3.00 & & \\
\hline Clearer & 12.00 & 20.00 & 17.00 & 33.00 & 10.00 & 6.00 & & \\
\hline Cleaning worker & 2.00 & 2.00 & 4.00 & 5.00 & 2.00 & 1.00 & & \\
\hline \multicolumn{9}{|l|}{ Experience years } \\
\hline$<5$ & 27.00 & 20.00 & 20.00 & 47.00 & 11.00 & 9.00 & \multirow[t]{2}{*}{16.88} & \multirow[t]{2}{*}{$<0.001^{* *}$} \\
\hline $5+$ & 12.00 & 10.00 & 11.00 & 26.00 & 5.00 & 2.00 & & \\
\hline \multicolumn{9}{|l|}{ Received training courses ( $n=42$ ) } \\
\hline Yes & 20.00 & 12.00 & 10.00 & 33.00 & 6.00 & 3.00 & \multirow[t]{2}{*}{12.86} & \multirow[t]{2}{*}{$<0.001^{* *}$} \\
\hline No & 10.00 & 8.00 & 40.00 & 23.00 & 5.00 & 28.00 & & \\
\hline \multicolumn{9}{|l|}{ No of courses $(n=42)$} \\
\hline$<3$ & 11.00 & 9.00 & 2.00 & 19.00 & 3.00 & 0.00 & \multirow[t]{2}{*}{18.52} & \multirow[t]{2}{*}{$<0.001^{* *}$} \\
\hline$\geq 3$ & 10.00 & 10.00 & 0.00 & 17.00 & 3.00 & 0.00 & & \\
\hline
\end{tabular}

** Highly statistically significant difference $(\mathrm{P}<0.001)$. 
Table 7. Relations between the laboratory workers total practices scores \& their socio-demographic characteristics and training courses about laboratory safety $(\mathbf{n}=\mathbf{1 0 0})$

\begin{tabular}{|c|c|c|c|c|c|c|}
\hline \multirow{3}{*}{ Socio-demographic Characteristics } & \multicolumn{6}{|c|}{ Total practices scores } \\
\hline & \multicolumn{2}{|c|}{ Before- program (\%) } & \multicolumn{2}{|c|}{ After- program (\%) } & \multicolumn{2}{|c|}{ Chi-Square } \\
\hline & Satisfactory & Unsatisfactory & Satisfactory & Unsatisfactory & $X^{2}$ & P-value \\
\hline \multicolumn{7}{|l|}{ Educational level } \\
\hline Basic education & 9.00 & 17.00 & 19.00 & 8.00 & & \\
\hline Secondary education & 20.00 & 23.00 & 36.00 & 8.00 & 95.25 & $<0.001^{* *}$ \\
\hline University education & 8.00 & 7.00 & 12.00 & 3.00 & & \\
\hline Postgraduate & 9.00 & 6.00 & 13.00 & 2.00 & & \\
\hline \multicolumn{7}{|l|}{ Nature of work } \\
\hline Laboratories Doctor & 7.00 & 4.00 & 10.00 & 1.00 & & \\
\hline Technician Nurse & 22.00 & 11.00 & 30.00 & 3.00 & 58.54 & $<0.001 * *$ \\
\hline Clearer & 20.00 & 29.00 & 39.00 & 10.00 & & \\
\hline Cleaning worker & 3.00 & 5.00 & 6.00 & 2.00 & & \\
\hline$<5$ & 29.00 & 38.00 & 50.00 & 17.00 & 11.00 & $<0.001 * *$ \\
\hline $5+$ & 19.00 & 14.00 & 26.00 & 7.00 & & \\
\hline \multicolumn{7}{|l|}{ Received training courses $(n=42)$} \\
\hline Yes & 22.00 & 20.00 & 36.00 & 8.00 & 18.56 & $<0.001^{* *}$ \\
\hline No & 26.00 & 32.00 & 34.00 & 24.00 & & \\
\hline \multicolumn{7}{|l|}{ No. of received courses $(n=42)$} \\
\hline$<3$ & 10.00 & 12.00 & 19.00 & 3.00 & 16.43 & $<0.001 * *$ \\
\hline$\geq 3$ & 11.00 & 9.00 & 17.00 & 30.00 & & \\
\hline
\end{tabular}

** Highly statistically significant difference $(\mathrm{P}<0.001)$.

Table 8. Correlation coefficient between total knowledge scores of the studied laboratory workers and their total practices scores regarding prevention of laboratory hazards pre and post program $(n=100)$.

\begin{tabular}{|c|c|c|c|c|}
\hline Variables & \multicolumn{2}{|c|}{ Total Knowledge Scores/ Pre } & \multicolumn{2}{|c|}{ Total Knowledge Scores/ Post } \\
\hline r / P-value & $\mathrm{r}$ & P-value & $\mathrm{r}$ & P-value \\
\hline Total Practices Scores/ Pre & 0.867 & $0.001 * *$ & \multicolumn{2}{|c|}{---------- } \\
\hline Total Practices Scores/ Post & & & 0.973 & $0.001^{* *}$ \\
\hline
\end{tabular}

**Highly statistically significant difference $(\mathrm{P}<0.001)$.

\section{Discussion}

The clinical laboratory is a workplace where many occupational hazardous such as chemicals, complex instrumentation, and potential pathogens are encountered on a daily basis. However: the laboratory can be a safe place to work and learn if possible hazards are identified; safety and infection control protocols are followed. Education of health care professionals about the general prevalence, risk of transmission, and availability of prophylaxis and treatment is imperative. Knowledge related to the importance of taking basic precautions through the use of gloves, gowns, and masks has been proven to decrease exposure incidents elsewhere, and should also prove to be effective in Egypt [16].

Regarding to demographic characteristics of the studied laboratory workers, more than of half of them aged from 30 to less than 40 years old, more than two thirds of them were male. As regard experience years; more than two thirds of them had less than five years of experience. Income was enough for more than two fifth, while weren't enough for only more than one third of them. These findings were not in accordance with [17], who studied" Assessment of profession hazards regarding medical laboratory in Taraboloss city in Libya" and pointed out that, most of the studied laboratory workers aged 20-30 years, about two thirds of them were female, and most of them had less than ten years of experience years.

The result revealed that, more than one third of the studied laboratory workers received training courses about laboratory safety measures. This finding in line with [18] who studied" Knowledge, attitudes and practices of health care personnel towards waste disposal management at Ain Shams University Hospitals, in Egypt and reported that, nearly two thirds of the nurses had received training regarding laboratory safety measures. While less than one fifth of the doctors and only one tenth of the lab technicians had received this training. None of the sanitary staff had reported about any training in relation to laboratory safety measures. This might be laboratory safety measures training of both the technical staff and the nontechnical staff is critical for the proper and appropriate management of laboratory safety measures.

As regards number of courses: more than half of the studied laboratory workers received less than 3 courses while less than of them received 3 courses or more. These results in the line with study conducted by [19] who studied "Quality of laboratory was conducted in clinical microbiological laboratories of four $\mathrm{MOH}$ (Ministry of Health) hospitals in Alexandria "and founded that, slightly less than one-third of the studied sample received one or more training courses on Universal Precautions (UP) 
included lab safety measures while none of cleaning workers received any type of previous training. This could be laboratory safety measures training and close monitoring are not the only solution; increasing the social expectation for mass education, increased motivation, and a firmer sense of ethics among laboratory workers will reduce or prevent laboratory hazards.

According to the place of courses more than two fifth of the studied laboratory workers taken the courses inside the hospital. This result was supported by [20] who studied "knowledge and awareness of routine biosafety measures and proper waste disposal Practices among healthcare workers in Karachi, Pakistan" and they found that, all the studied laboratory workers taken the courses inside the hospital. This might be the studied laboratory workers who were completely unaware of lab safety knowledge and biosecurity practices and needed education about personal safety, appropriate handling and lab safety measures to prevent lab hazards inside the hospital.

The present study revealed that; the studied laboratory workers according to their educational levels, more than two fifth of them had secondary education while about one quarter of them had basic education, and more than tenth of them had high education and post graduate. These results disagree with study conducted by [4] who studied" Safety measures at post gradates in institutes of Alexandria University and found that, less than half of the studied sample had high education; post graduate; more than half of them had secondary education.

Regarding the laboratory workers categories according to their nature of job, the present study revealed that; less than half of them were employee while one third of them were technician workers and tenth of them were laboratories doctor, and only $8 \%$ were cleaning workers. These results disagree with study conducted by [19] who studied safety measures Bacteriological Laboratories/-Quality at Alexandria University and found that, Among 37 laboratory staff, less than half of the studied sample were physicians, more than half of them had were technicians, with different scientific degree.

Regarding studied hospitals laboratory condition, all of the studied hospitals laboratory had tap water supply, while three quarters of them had clean laboratory area, clean tables, suction fans for ventilation, label code and precaution on chemical substances, soft wired nets on the windows, and good lightening in the Lab and more than one fifth of them had clean laboratory equipment, and keep equipment in clean and safe place. These finding disagreed with [21] who studied evaluating effectiveness of occupational safety and health measures in the scientific laboratories in the Palestinian Universities in Gaza strip: a filed study and they founded that, more than two thirds of the studied hospitals laboratory had tap water supply, while less than two thirds of them had clean laboratory area, clean tables, suction fans for ventilation, label code and precaution on chemical substances, soft wired nets on the windows, and poor lightening in the lab and less than half of them had clean laboratory equipment.

This might be when the laboratory's safe environment under suitable conditions, such as suitable area, availability of facilities, and good degree of cleanliness, sufficient lighting and ventilation, and the staff performance in these suitable safety environments would significantly be better and correct.

The result of the present study revealed that; the studied laboratory workers' knowledge regarding to laboratory health hazards chemical, biological, physical, mechanical, ergonomic, electrical, and psychological hazards improved significantly after the program implementation $(\mathrm{P}<0.001)$. These results agree with study conducted by [22] who studied the "Awareness and practices regarding biomedical waste management among health care workers in tertiary care hospital of Haldwani, Nainital" and found that, the studied laboratory workers' knowledge regarding to biological laboratory hazards improved significantly after the program implementation $(\mathrm{P}<0.001)$. This might be due to the success of lab safety measures programme depends on the both knowledge and practice of the studied laboratory workers.

The present study revealed that, the studied laboratory workers' knowledge regarding to laboratory chemical hazards, The results of the study disagree with study conducted by [4] who studied " Laboratory chemical safety measures at postgraduates" in Institutes of Alexandria University and found that, the studied laboratory workers' knowledge regarding to chemical laboratory hazards improved but not significantly after the program implementation ( $\mathrm{P}<0.001)$.

According to [23] who mention that; lab environment contain hazardous include fire, breakage of glassware, sharps, spillages, Pressure equipment \& gas cylinders, extremes of heat \& cold, chemical hazards, biological hazards and radiation. So, the nurse must be educate the lab worker's to important follow the control measures in order of preference as use a less risky substance, use a safer form of that substance (e.g solution instead of powder, Totally enclose the process (eg a glove-box), partially enclose the process (eg with a fume cupboard), ensure good general ventilation, safe systems of work, reduce exposure times, increase distance, reduce volumes and personal protective equipment (as a last resort for primary protection.

Regarding to the studied laboratory workers' knowledge about laboratory safety (general personal safety, eye safety, safe handling of biological hazardous material, chemical and gas safety, radiation safety, fire safety, electrical safety, severe weather safety, and in case of accidents improved significantly after the program implementation $(\mathrm{P}<0.001)$. These findings was agreement with (5] who studied "Quality management in medical laboratory in the Arabic World and reported that studied laboratory workers' knowledge about laboratory safety (general personal safety, eye safety, safe handling of biological hazardous material, chemical and gas safety, radiation safety, fire safety, electrical safety, severe weather safety, in case of accidents and improved significantly after the program implementation $(\mathrm{P}<0.001)$.

Furthermore, the present study revealed that; laboratory studied workers' total knowledge score regarding laboratory safety, before the program implementation; more than one fifth of the studied laboratory workers had good total knowledge scores regarding laboratory safety, while after the program implementation total knowledge scores increased to about two third of the studied laboratory workers. This result agree with the study conducted by [25] 
who studied "Improvement of knowledge, attitudes and practices of health care workers towards the transmission of blood-borne pathogens" and found that, studied laboratory workers as lab technicians had the best level of knowledge in the pre-intervention phase followed by the nurses, while after the program implementation had good total knowledge scores regarding laboratory safety, increased to three quarters. This finding agreement with [25] who studied" Knowledge, attitude and practices of bio-medical waste management amongst staff of institutional trauma center level II in C. S. M. Medical University, Lucknow", and found that less than one fifth of the laboratory workers had good total knowledge scores regarding laboratory safety, while after the program implementation total knowledge scores increased to less than two thirds.

The present study revealed that; laboratory safety practices as reported by the studied laboratory workers, the variable "laboratory dress code policy "were done completely for more than one third of the studied laboratory workers before the program while improved in most of them after the program implementation. While eating, drinking, and applying cosmetics (personal habits) in the laboratory are very common in more than half of studied lab worker before program implementation, to increase the variable "good personal habits" after the program implementation in most of the studied laboratory workers. But these practices were prohibited in only $25(10 \%)$ of the labs. These results supported by [27] who studied " The impact of applying ISO.15189 standard of quality and competence of medical laboratories on patients satisfaction in the Jordanian private medical laboratories" and found that; variable "good personal habits" and "laboratory dress code policy "were done completely for more than one third of the studied laboratory workers before the program implementation while improved in most of them after the program implementation.

According [29] who mentioned that; gowns made of impervious material are worn to protect the wearer's clothing/uniform from possible contamination with micro-organisms and exposure to blood, body fluids secretions and excretions, and an apron protects the wearer and the uniform from contact with the contaminated body fluids. Plastic aprons are used over the gown when taken lab sample where possible splashes with blood and body substances may occur in the lab.

Although the Lab Director establishes policies and procedures for potential biohazards and biosafety measures. This might be studied laboratory workers that those policies were not comprehensive or implemented consistently in this study.

The present study revealed that, the variable "decontamination procedure" was less than half of studied laboratory workers before the program implementation and increased to more than three quarters of them after the program. This result in the line with [20] who studied "Knowledge and awareness of routine biosafety measures and proper waste disposal Practices among healthcare workers in Karachi, Pakistan" and who found that, studied laboratory workers practices improved after the program in labs decontaminate as seventy percent $(70 \%)(n=175)$ of the labs decontaminate work surfaces daily, while $22 \%(n=55)$ decontaminate cultures. Approximately, 67.2\%
( $n=168$ ) of the labs decontaminate lab equipment using an effective disinfectant; $2 \%(n=18)$ properly decontaminate spills involving infectious materials; and $10 \% \quad(n=25)$ decontaminate equipment and materials before removal from the lab. Cultures, specimens, and body fluids are placed in proper leak-proof containers during work and transportation in $90 \%(n=225)$ of labs.

Additionally, the present study result disagree with [19] who studied "Quality of laboratory was conducted in clinical microbiological laboratories of four $\mathrm{MOH}$ (Ministry of Health) hospitals in Alexandria "and founded that, absence of formal documented training program for orientation of new employees and continuous education and training programs. So; low level of the staff knowledge. This might be documentation is deficient in all laboratory areas including policies and procedure for specimen management, test process, quality control, equipment management, reagent management, verbal/telephone orders or reporting system, laboratory safety program, hazardous material and waste management.

Regarding to laboratory safety practices by the studied laboratory workers, the "good laboratory technique and good housekeeping practices" were two fifth of them before the program implementation and increased to three quarters after the program. There were high statistically significant differences $(\mathrm{P}<0.001)$. These findings agreement with [22] they mention that, as regards good laboratory technique and good housekeeping practices" were more than one third of sample before the program implementation and increased to three quarters after the program. There were high statistically significant differences $(\mathrm{P}<0.001)$

The result of the present study revealed that; studied laboratory workers' total practices scores before the program implementation; only less than half of them had satisfactory practices regarding laboratory safety measures, while after the program implementation increased tendency to three quarters. This result supported by [28] in Egypt and who found that, laboratory workers' total practices scores before the program implementation; only less than one third of them had satisfactory practices regarding laboratory safety measures, while after the program implementation increased tendency to half of them. Also, this result agree with the study conducted by [25] who studied "Improvement of knowledge, attitudes and practices of health care workers towards the transmission of blood-borne pathogens" in Egypt and found that, the practice score of the nurses and lab technicians significantly increased following the intervention. The marked improvement of the practice score by nearly one third (from two third to most of them) and nearly one fifth (from two third to most of them) among the lab technicians and nurses respectively.

According to [23] who mentioned that, standard precautions consider every person (patient/clients or staff) as potentially infectious and susceptible to infection, use appropriate hand hygiene techniques including; routine hand washing, wear personal protective equipment which include: boots, aprons, gowns, gloves, masks, protective eyewear and caps, appropriately handle sharps, patient care and resuscitation equipment, and appropriately manage patient placement and environmental cleaning, safely dispose of infectious waste materials to protect those who handle them and prevent injury or spread to the 
community and process instruments by decontamination, cleaning, and either sterilization or high-level disinfection following recommended procedures.

Relations between the laboratory workers' total knowledge scores, their demographic characteristics and training courses about laboratory safety. There were high statistically significant differences between the studied laboratory workers' total knowledge scores and their age, gender, educational levels, nature of job, experience years, and their received training courses $(\mathrm{P}<0.001)$. These results in the line with study conducted by [19] who studied quality of laboratory was conducted in clinical microbiological laboratories of four MOH (Ministry of Health) hospitals in Alexandria and founded that, the years of experience and training program are significantly affecting the level of studied laboratory workers, where the lab staff who has $10<$ years of experience and with training program showed best test results and performance level.

Relations between the studied laboratory workers total practices scores their demographic characteristics and training courses about laboratory safety, the result of the present study revealed that; there were highly statistically significant differences between total practices scores of the studied laboratory workers regarding prevention of occupational hazards and their educational levels, nature of job, experience years, and their received training courses $(\mathrm{P}<0.001)$. This might be because the laboratories as any workplaces contain numerous hazards as well as ergonomic disease. These hazards have to overcome to make safer laboratories requires mandatory rules, training programs and laboratory workers with experience.

According to [16] promulgated the OSHA laboratory safety standards Worldwide. Laboratory safety requires mandatory rules, training programs a commitment to them and expectation of the consequences when those rules are not met. Institutions need well developed structures and supports that extend beyond the laboratory well to the institution it-self. The responsibility safety rests ultimately with head of the institution and its operating units, chemical safety officer, laboratory managers, supervisors, technicians and all lab workers.

Finally, the current study revealed a highly significant statistical difference between total knowledge scores of the studied laboratory workers and their total practices scores regarding prevention of laboratory hazards $(\mathrm{P}<0.001)$. This result was supported by [20] who studied "Knowledge and awareness of routine biosafety measures and proper waste disposal practices among healthcare workers in Karachi, Pakistan" and they found that, a highly significant statistical difference between total knowledge scores of the studied laboratory workers and their total practices scores regarding prevention of occupational hazards $(\mathrm{P}<0.001)$. This might be overall satisfaction with the training program and the competence of the coordination team were rated very well by a majority of the studied laboratory workers.

\section{Conclusion \& Recommendation}

This study and research hypotheses concluded that the training safety program has positive effect to upgrade the laboratory workers' knowledge and improving their practices regarding prevention of laboratory hazards and safety environmental condition hazards $(\mathrm{P}<0.001)$. The study recommended that regulatory training program should be strengthened to ensure basic lab safety practices in hospitals, and make training courses for large number of hospitals laboratory workers about prevention of laboratory hazards safety environmental condition.

\section{References}

[1] Centers for Disease Control and Prevention. (CDC, 2016): Occupational hazards. Available at:

https://www.cdc.gov/niosh/about/. Accessed on 24 June 2018.

[2] University of Utah Environmental Health and Safety, (2017): Environmental health and safety, Available at: http://www.ehs.utah.edu. Last accessed 28 June 2017.

[3] The Committee on Prudent Practices in the Laboratory, (2016): Handling and management of chemical hazards. national research council. prudent practices in the laboratory: The National Academies, Washington, D.C. www.nap.edu. The National Academy of Sciences. Available at: http://nap.edu/12654. Accessed on: 21 June 2016.

[4] Awad O., (2017). Assessment of chemical laboratories safety measures at postgraduates. Institutes of Alexandria University. Master of public health sciences in occupational hygiene and air pollution. P.72.

[5] Zquipa S., (2017).Quality management in medical laboratory report. Available at: http:mawdoo3.com. Accessed on 5/2018.

[6] James S., and Natalia A. (2014). Microbiology a laboratory manual. $10^{\text {th }}$. Community College. Boston. P. 213. Available at: http:// lab Safety.Preacaution.com. Accessed on: 4/2018.

[7] Luebbert J. (2018). Containing chemical spills. Advance for laboratory administrators, pp. 20-25. Available at: http://laboratorymanager.advanceweb.com/Article/CautionFlamm able.aspx. Last accessed 21 May 2018.

[8] Basavanthappa, B. (2016). Community Health Nursing, $3^{\text {ed }}$. The healthy science publisher. London. 2(1). P.12. Available at: www.jaypeebrothers.com. Accessed on: 4/2018.

[9] Norsk D. (2018).Precautions and safety measures. Available at: https://www.uib. Accessed on: 5/2018.

[10] Occupational Safety and Health Administration. OSHA. (2011) Fact Sheet. Laboratory Standard. Available at: www. osha.gov.Accessible at: 5/2018.

[11] Sridhar R., (2017). Community health nursing, volume 2, $3^{\text {th }}$. The healthy science publisher. Aitbs. Indiap. Available at: www.jaypeebrothers.com. Accessed on: 4/2018.

[12] Centers for Disease Control and Prevention (CDC, 2016a): U.S. Department of Health and Human Services. The National Institute for Occupational Safety and Health (NIOSH). NIOSH Science Blog: N95 Respirators and Surgical Masks. http://blogs.cdc.gov/niosh-science-blog/2009/10/14/n95/.Accessed 15 June 2016.

[13] Babanyara Y., Ibarhim D., Garba T., Bogoro A., and Abubakar M. (2013): Poor medical waste management (MWM) practices and its risks to human health and the environment: A Literature Review World Academy of Science, Engineering and Technology International Journal of Environmental, Ecological, Geological and Geophysical Engineering 7(11). University, Bauchi, Nigeria.

[14] WHO, (2017). "Safe health care-waste management policy paper. Available at: www.healthcarewaste.org. Access on $20^{\text {th }}$. March, 2018.

[15] Bishop, Michael L., Fody, Edward P., Schoeff, and Larry E. (2013). Clinical Chemistry, 7th Ed. Laboratory Safety and Regulations, pp 36-51. Lippincott Williams and Wilkins. II International Journal of Research in Health Sciences. (Supplement) July -Sept 2013; 1(2). P. 23.

[16] The National Institute for Occupational Safety and Health (NIOSH), (2016). Centers for Disease Control and Prevention (2016): U.S. Department of Health and Human Services. NIOSH Science Blog: N95 Respirators and Surgical Masks. http://blogs.cdc.gov/niosh-science-blog/2009/10/14/n95/. Accessed 15June 2016. 
[17] Abode, A. (2013). "Assessment of profession hazards regarding medical laboratory in Taraboloss City in Libya". Available at: http://edicalwaste.org.ly. Accessed on: 5/2018.

[18] Hakim A., Mohsen I., and Bakr L. (2014). Knowledge, attitudes and practices of health-care personnel towards waste disposal management at Ain Shams University Hospitals, Cairo. Eastern Mediterranean Health Journal 2014. Vol .20 (5): 347-354.

[19] Saber A., Zenhom I., Nasrm., and Moustafa S. (2012). Bacteriological Laboratorie-Quality, Alexandria University. High Institute of Public Health -Department of Microbiolog. P.74.

[20] Nadeem S., Hakim S., and Tayyab S. (2014). Knowledge and awareness of routine biosafety measures and proper waste disposal practices among healthcare workers in Karachi, Pakistan and Shahana Urooj Kazmi2 1Jinnah University for Women, Karachi, Pakistan and 2University of Karachi, Karachi, Pakistan 1 Jinnah University for Women available at: http.//www.absa.org. vol.17, no4.

[21] Aish and El-Habile (2012). Evaluating effectiveness of occupational safety and health measures in the scientific laboratories in the Palestinian Universities in Gaza strip: a filed study. P.12.

[22] Singh, R., Kumar, M., Rawat, V., and Umesh, M. (2015) "Awareness and practices regarding biomedical waste management among health care workers in tertiary care hospital of Haldwani, Nainital" P.10. Available at: NATIONAL JOURNAL
OF MEDICAL RESEARCH print ISSN: 22494995 | ISSN: 2277 8810 NJMR

[23] Sridhar R., (2017. Community health nursing, volume 2, $3^{\text {ed }}$. The healthy science publisher. Aitbs. India. P. Available at: www.jaypeebrothers.com. Accessed on: 4/2018.

[24] Saleh D., Elghorory M., Shafik R., and Elsherbini E. (2009). Improvement of knowledge, attitudes and practices of health care workers towards the transmission of blood-borne pathogens: An Intervention study department of community Medicine, Faculty of Medicine, Cairo, Egypt ** United Nations Development Program. Available at: J Egypt Public Health Assoc. Vol. 84 No. 5 \& 6, 2009.

[25] Ajai and Nath, (2013). Knowledge, attitude and practices of biomedical waste management amongst staff of institutional trauma center level II in C. S. M. Medical University, Lucknow". P.

[26] Al-Sharawneh, R. (2013). The impact of applying ISO standard of quality and competence of medical laboratories on patients satisfaction in the jordanian private medical laboratories. Masr. P.51.

[27] Althabete A. (2016). Medical laboratory hazards on individuals and environment. Available at: edicalwaste.org.ly. Trebles University. Labia. P. Accessed on: 5/2018.

[28] WHO, (2018). Occupational health" Laboratory technician and technologist" Available at: https://www.who.int Access on $20^{\text {th }}$. March, 2018. P.

C The Author(s) 2019. This article is an open access article distributed under the terms and conditions of the Creative Commons Attribution (CC BY) license (http://creativecommons.org/licenses/by/4.0/). 